\title{
Analysis on the Industrial Development Plan of the Tribal Hot Spring Demonstration Area in Taiwan's Indigenous Areas
}

\author{
Hsiao-Ming Chang1, Chin-Lung Chou ${ }^{2}$, Mao-Chun Chiu ${ }^{3 *}$ \\ ${ }^{1}$ School of Physical Education, Putian University, Putian, China \\ ${ }^{2}$ Department of Tourism Leisure and Health, Ching Kuo Institute of Management and Health, Keelung, Taiwan, China \\ ${ }^{3}$ Department of Recreational and Sport Management, Tajen University, Pingdong, Taiwan, China \\ Email: 1815649662@qq.ocm, rocjkl@yahoo.com.tw, *cfchiu@tajen.edu.tw
}

How to cite this paper: Chang, H.-M., Chou, C.-L. and Chiu, M.-C. (2021) Analysis on the Industrial Development Plan of the Tribal Hot Spring Demonstration Area in Taiwan's Indigenous Areas. Open Journal of Applied Sciences, 11, 58-71.

https://doi.org/10.4236/ojapps.2021.111005

Received: December 19, 2020

Accepted: January 17, 2021

Published: January 20, 2021

Copyright ( $) 2021$ by author(s) and Scientific Research Publishing Inc. This work is licensed under the Creative Commons Attribution International License (CC BY 4.0).

http://creativecommons.org/licenses/by/4.0/

\begin{abstract}
Under the impact of modern life, the traditional culture of Taiwan's indigenous tribes is not only affected, because the traditional life is not easy and employment is difficult, which also causes the outflow of tribal population. Therefore, after the establishment of the Taiwan Council of indigenous people (TCIP), tourism development has been listed as an important policy, and it wants to use tourism development to improve the lives of indigenous people and enhance the ability of tribal economic development. The purpose of this study is to analyze the advantages and disadvantages of TCIP in developing tribal hot spring demonstration areas in indigenous areas. This study adopts the method of case study to investigate by means of document analysis, field interview and observation. The results of SWOT analysis show that: 1) Advantages: the indigenous tribes are rich in natural resources and have unique cultural characteristics. 2) Weakness: when indigenous people invest in hot spring industry, they will face difficulties in obtaining development funds, lack of land use and hot spring management talents. 3) Opportunities: Because of the prevailing leisure culture in Taiwan, coupled with the relevant laws and policies and plans of the indigenous people, it is guaranteed that the indigenous people can participate in the development plan of the hot spring demonstration area. 4) Threats: The development of the existing hot springs in the indigenous villages and towns is mostly invested by the Han people, so it is difficult for the indigenous people to compete with them. Moreover, they lack the management ability and guidance to enter the competitive market of hot spring development.
\end{abstract}

\section{Keywords}

Hot Spring, Tribal Tourism, Industrial Development, Indigenous 


\section{Introduction}

There are 16 indigenous ethnic groups in Taiwan. Each ethnic group has its own culture, language, customs and social structure. In the face of modern social changes and the invasion of global capitalism, due to the fact that most of the areas inhabited by indigenous people are located in remote and economically underdeveloped areas, and the traditional life of the tribe is not easy, the employment difficulties lead to the serious outflow of the young population of the tribe and the continuous loss of traditional culture [1]. Moreover, due to the economic weakness of the indigenous people and the long-term stereotype of the Taiwan people, they are unable to gain cultural identity and support. As a result, the indigenous people are more engaged in labor-related work, with high unemployment rate, high dropout rate and high alcohol drinking rate [2]. According to TCIP, with the awakening of the self-identity consciousness of the indigenous people, many tribes began to think about how to restore the traditional wisdom and lifestyle of their ancestors, and at the same time, they could revive the impoverished economy of the tribe in the form of industry, so that the indigenous youth would like to return to their land to live. Because the number of tribes is located in high mountains, it has rich hot spring resources. If it can combine the characteristics of the indigenous culture and improve the restaurants and B \& B of the tribe, it is the most potential for development [3]. TCIP believes that under the promotion of hot spring development, the development in the form of tribal characteristics rather than blindly pursuing the tourism experience of large-scale development type can create unique and unique hot spring tribal development forms [4]. According to the above, this paper first analyzes the current situation of hot spring development in Taiwan, analyzes the current situation of the tribal hot spring demonstration area selected by TCIP, as well as the local resources, advantages and problems of the hot spring with development characteristics of the tribe, hoping that the analysis results can provide reference for research and practical operation. The following research is divided into Taiwan hot spring development status, tribal hot spring demonstration area status, tribal hot spring with development characteristics of the SWOT analysis, the final conclusion and suggestions.

\section{Hot Spring Development in Taiwan}

Taiwan is located in the collision zone between the Eurasian plate and the Philippine Sea plate. The geology and structure of the island are complex and rich in hot spring resources. The development and utilization of hot springs in Taiwan can be divided into four periods [5]: Qing Dynasty, Japanese colonial rule, geothermal exploration and leisure tourism. In 1893, Ouely, a German, opened a club in Beitou, which was the beginning of Taiwan's hot spring hotel. After entering the Japanese colonial period, the development of hot springs in Taiwan was relatively large. For example, the well-known Beitou hot spring, Tai'an hot spring, Jiaoxi hot spring, Qingquan hot spring, Guanziling hot spring, Sichongxi 
hot spring, Zhiben hot spring, etc. were discovered and developed during the Japanese occupation, and now they have become important hot spring areas in Taiwan. After the National Government came to Taiwan, the development of hot springs in Taiwan can be divided into two periods: geothermal exploration for national use and leisure and tourism now. In the 1980s, hot spring hotels have sprung up like mushrooms in the leisure life oriented society of Taiwan. With the improvement of hot spring hotel facilities and the attraction of hot spring baths to customers, hot spring soup has become a popular leisure activity for most people.

The hot springs in Taiwan can be roughly divided into six categories, of which carbonated springs are the most widely distributed, such as Renze hot spring in Yilan County, Suao cold spring, Wulai hot spring in New Taipei City, Simian hot spring in Taoyuan City, Qingquan hot spring in Hsinchu County, Taian hot spring in Miaoli County (see Figure 1).

In the central area, Guguan Hot Spring in Taichung City (see Figure 2), Lushan and Dongpu hot spring in Nantou County (see Figure 3 and Figure 4); in the southern region, Dagangshan Bulao hot spring, Baolai hot spring, and Xuhai hot spring of Sizhongxi in Pingdong county. And Wenshan and Hongye hot

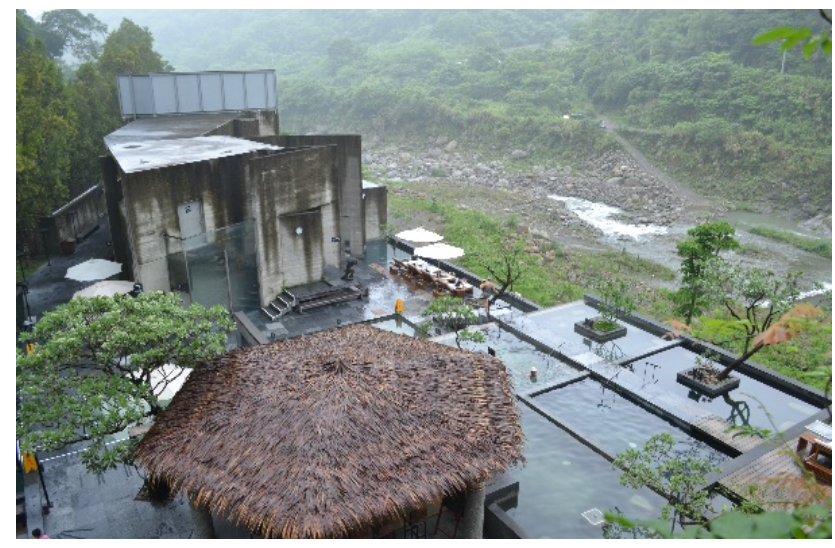

Figure 1. Taian hot spring area (Onsen Papawapa Hot Spring Hotel).

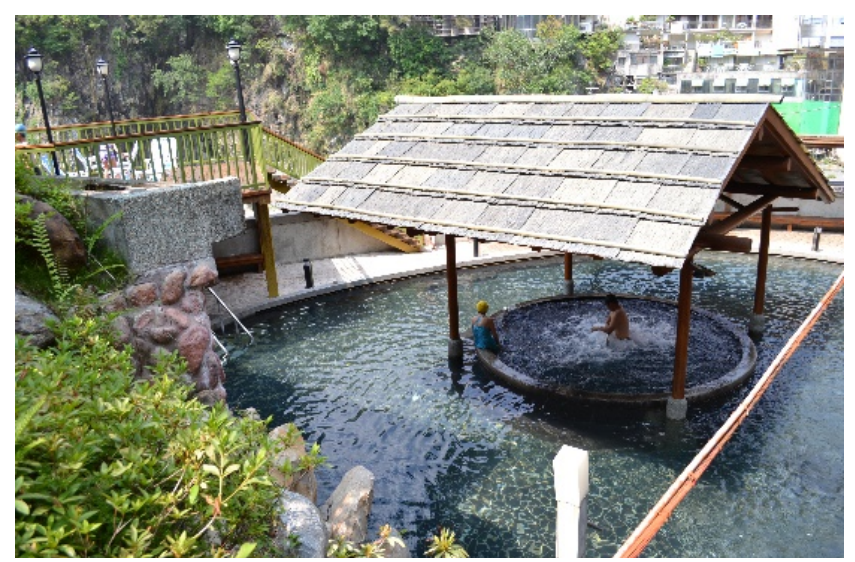

Figure 2. Guguan hot spring area. 


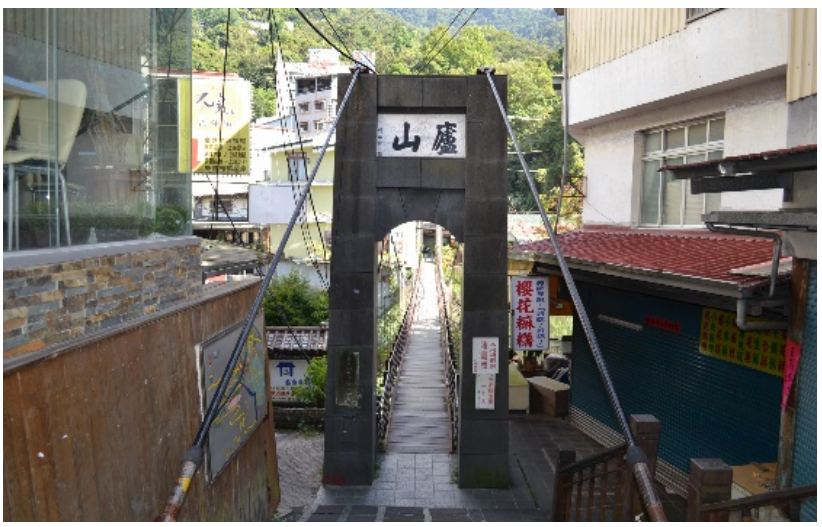

Figure 3. Lushan hot spring area.

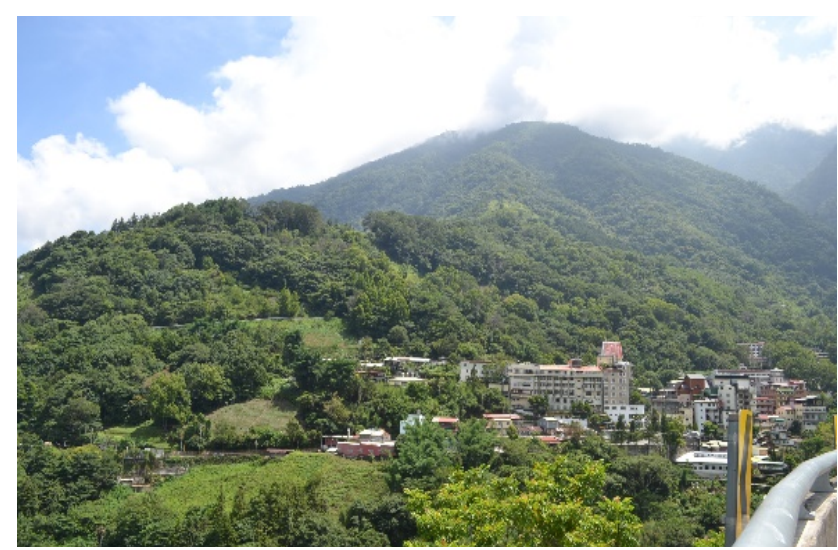

Figure 4. Dongpu hot spring area.

springs in Hualian county and Luwu hot spring in Taitung County in the East. Iron spring has Ruisui hot spring in Hualian County in the East Taiwan. The sodium bicarbonate spring, there are Jiaoxi hot spring in Yilan County, Wulai hot spring in New Taipei city and Chihpen hot spring in Taitung County in the East Taiwan (see Figure 5). In terms of Chlorsulfuron spring, there are Wanliao hot spring in New Taipei City, Yangmingshan hot spring in Beitou, Chaori hot spring in Green Island, Taitung County in the East Taiwan. In the southern area of Tainan City, Guanzilin hot spring area is a turbid spring (see Figure 6). In the eastern part of Hualian County, Antong hot spring is a salt hydrogen spring [6]. However, although there are many hot spring areas with good quality and abundant springs in Taiwan, there was a lack of effective development and management before; the lack of public facilities, the arbitrary erection of hot spring pipelines, the disordered overall landscape of the hot spring area, and the high proportion of illegal hot spring hotels. The "Hot Spring Law" promulgated by Taiwan Executive Yuan on July 2, 2003 has a certain influence on the management strategy of hot spring managers. In addition, Taiwan's Tourism Bureau lists the planning of hot spring areas, as well as the promotion and marketing of hot spring products, as one of the tourism policies, such as promoting "Hot Spring Food Carnival", "Hot Spring Tourism Year" and "Hot Spring Food 


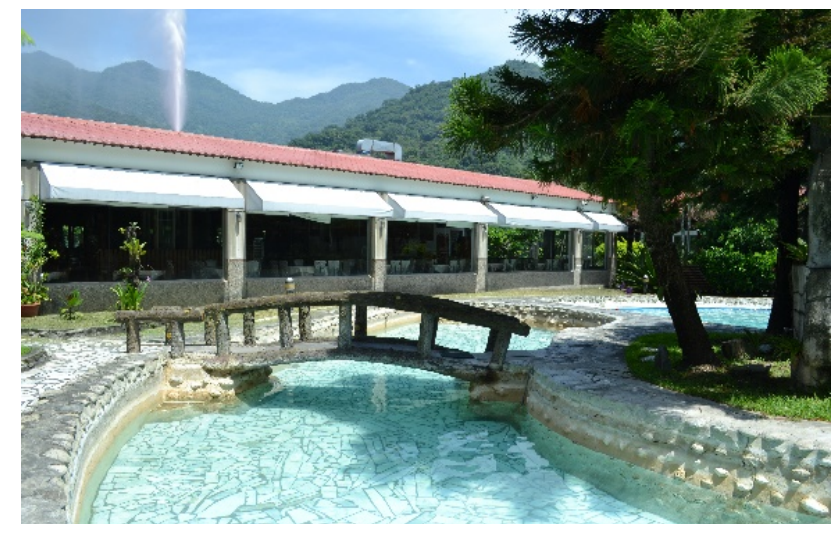

Figure 5. Chihpen hot spring (rainbow resort).

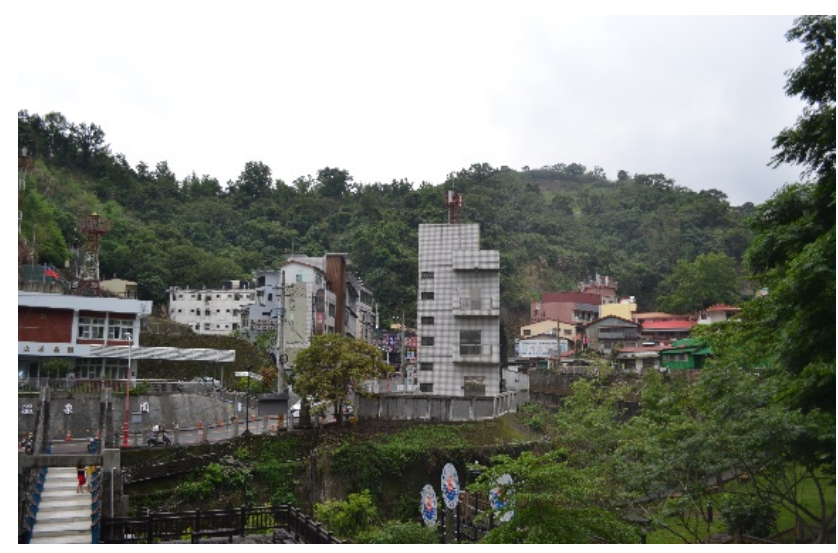

Figure 6. Guanzilin hot spring area.

Health Tour”.

\section{Research Methods}

This study mainly uses three research methods, the first is literature analysis, the second is observation, the third is interview. They are described below.

\subsection{Documentary Analysis Method}

Through the website of the indigenous people, we can understand the reasons why six indigenous areas have been selected as hot spring demonstration areas in the "three-year plan for economic and industrial development of indigenous people (2010-2012)" proposed by the former association of democracy in 2010, as well as the policy background. Secondly, through web search, we can learn about the hot spring demonstration area and the development of local tribal tourism.

\subsection{Observation Method}

In the second stage of this study, six indigenous areas were selected as hot spring demonstration areas, including Hsinchu hot spring in Jianshi Township of Hsinchu County, Meiyuan and Tiangou hot spring in Taian Township of Miaoli 
County, Lover Square hot spring in Maolin District of Kaohsiung, Lintianshan hot spring in Wanrong Township of Hualian County, Yeheng hot spring and Luofu hot spring in Fuxing Township of Taoyuan City, and Jinfeng hot spring in Jinfeng Township of Taitung County. Understand the actual development of the current situation, as well as whether the local tribal tourism is in line with the original policy planning objectives.

\subsection{Interview Method}

In the third stage of this study, we interviewed the indigenous people (tribal residents, leaders, B \& B and restaurant operators, Tribe Development Association) of the local tribes. The outline of the interview is as follows:

1) Do you know that the TCIP has a plan to develop the indigenous hot spring demonstration area?

2) What advantages do you think indigenous tribes have in developing hot spring tourism?

3) What are your disadvantages compared with the hot spring hotels run by Han people in the neighboring areas?

4) What do you think is the threat to the development of hot spring tourism by indigenous tribes? And where is the opportunity?

In this study, after the interview, we first make the interview data into a verbatim manuscript, and then analyze the results of literature analysis and actual observation. In order not to cause the subjective judgment of the researchers, the researchers adopt the way of joint analysis. In the SWOT, they try to get a consensus and then write the results of the analysis.

\section{The Current Situation of the Tribal Hot Spring Demonstration Area}

There are 135 natural hot springs in Taiwan, while 104 natural hot springs are exposed in the indigenous people areas. Therefore, the indigenous people areas have rich hot spring resources and beautiful scenery, and have great potential to develop hot spring industry. As the areas and tribes where the indigenous people are located are rich in national culture and natural ecological resources, the development of tribal tourism is the main policy focus. For example, the economic and industrial development of the indigenous people and the plan to promote the employment of the indigenous people list the development of the hot spring industry as the main goal of the administration. According to the implementation results of TCIP long-term five-year (2010-2014) implementation plan of hot spring resources in indigenous people, there are 22 indigenous villages and towns with hot spring development potential in Taiwan. The first category is the three indigenous hot springs that have received subsidies and become demonstration areas. The second category is the indigenous villages and towns located in the approved hot spring area, and the third category is the indigenous villages and towns not located in the hot spring area. According to the "three-years plan 
for economic and industrial development of indigenous people (2010-2012)" put forward by TCIP in 2010, six indigenous areas were selected as hot spring demonstration areas, which are described as follows [6].

\subsection{Hsinchu Hot Spring, Jianshi Township, Hsinchu County}

The scope of the project is located in Jianshi Township, Hsinchu county. Jianshi township is located in the southeast of Hsinchu county. It is one of the two mountain villages under the jurisdiction of Hsinchu County, with a total area of about 528 square kilometers, which is the largest township in Hsinchu county. Xiuluan hot spring is located in the valley outside Xiuluan village. The original hot spring has many springs beside the stream (see Figure 7). The water quality is very good. The spring temperature is about 40 - 50 degrees centigrade. It belongs to weak alkaline carbonate spring. Due to the inconvenient transportation, the development is very few. Only the village residents have built up stone walls and canvas sheds to cover up. Although it is only a simple bathing enclosure, it is quite primitive.

\subsection{Meiyuan and Tiangou Hot Spring in Taian Township, Miaoli County}

The geology of this area is located in the Western piedmont zone of Northern Taiwan. There is a Tiangou Fault in the west side of the base. The current data show that the Tiangou Fault is not an active fault. The survey area is located in the hanging wall of the Tiangou Fault. In the eastern part of the Tiangou tribe (see Figure 8), the possible hot spring reservoir is at least 200 or 500 meters below the surface, and may be located in the fractured rock plate adjacent to the Tiangou Fault in the lower part of Wenshui layer.

\subsection{Lover Square Hot Spring, Maolin District, Kaohsiung}

Maolin district is located in the southeast of Kaohsiung City, adjacent to Gaoshu township of Pingdong county. The biggest cultural feature of the area is the $\mathrm{Ru}$ kai nationality, one of the 16 aborigines in Taiwan. They live in Maolin, Wanshan

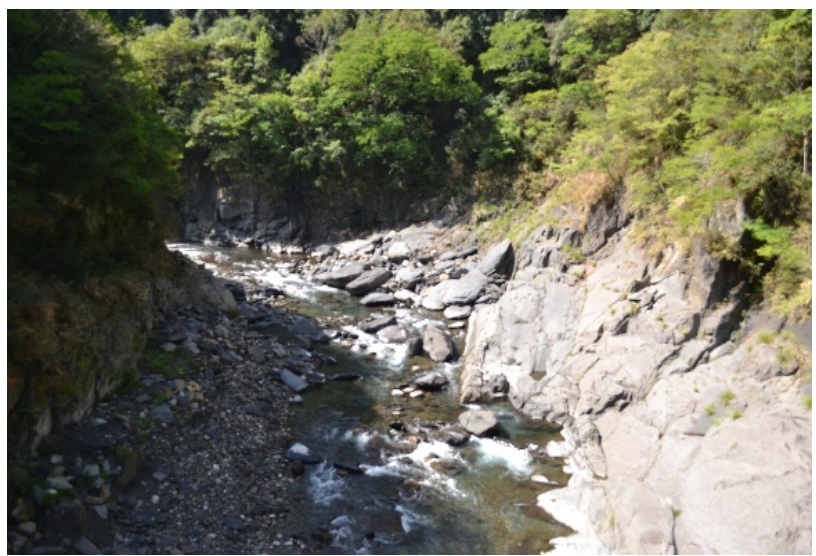

Figure 7. Xiuluan river. 


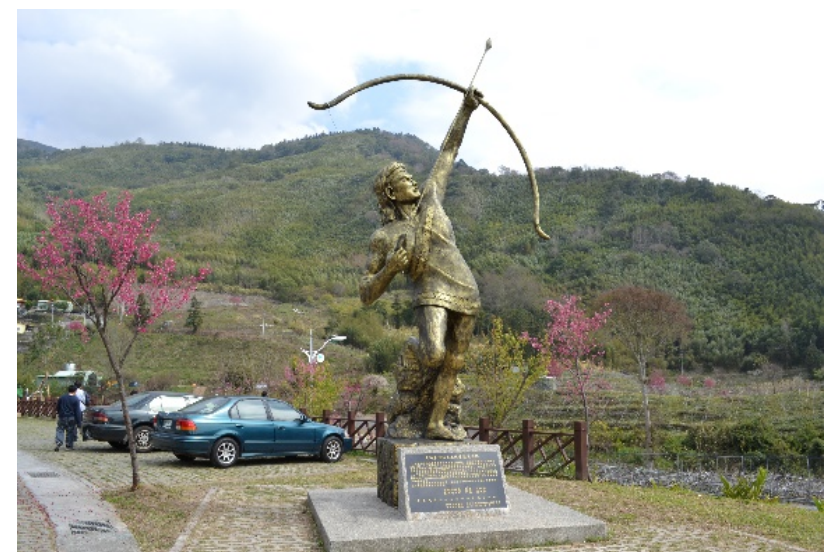

Figure 8. Tiangou tribe.

and Dona tribes. The proposed development base, Lover Square, is located to the south of Maolin district office. It is now a park with flat terrain, but the existing facilities are old and damaged. It is a kind of recreational land with permission to develop hot spring wells, and has obtained the hot spring development license.

\subsection{Lintianshan Hot Spring, Wanrong Township, Hualian County}

Wanrong township is located in the middle of Hualian County. It is located on the west side of the north section of Huadong longitudinal valley, Shoufeng Township in the north, Zhuoxi Township in the south, Fenglin, Guangfu, Ruisui and other towns in the East. It is a hillside terrain with a narrow north-south length of $45 \mathrm{~km}$, an average altitude of 600 meters, and a central mountain range in the West Besides agricultural products, it also has abundant hot spring resources. The hot spring outcrops recorded in Wanrong Township include Erzishan, Lejia, Wanrong (Yuanyang Valley), Fuyuan, Hongye, etc. Wanrong hot spring is located in the middle reaches of Wanliqiao River, and the hot spring omen extends for about 50 meters. Wanrong hot spring is distributed on both sides of Wanliqiao River, and mainly on the right bank. It comes out from the schist fissures with medium amount of bubbles. The hot spring is slightly high in iron, and the rocks near the outcrop are mostly reddish brown. Wanrong hot spring used to be called Yuanyanggu hot spring.

\subsection{Yeheng Hot Spring and Luofu Hot Spring in Fuxing Township, Taoyuan City}

According to the previous survey records in Fuxing Township, Taoyuan City, there are five hot springs, namely Ronghua hot spring, Yeheng hot spring, Xinxing hot spring, Xiaoxinxing hot spring and Sigu hot spring. The hot springs in the area are mainly distributed along the Dahan river or its upstream tributaries. The hot springs in the area are all sodium bicarbonate springs, and most of them come out of the surface along the valley lowlands. The quality of Luofu hot spring is sodium bicarbonate spring, which can help to keep beauty, relax mood 
and regulate body. At present, the municipal government is promoting citizens to go to Luofu hot spring for free to experience Luofu hot spring. In the future, "Luofu Hot Spring Street" will also be developed to promote the hot spring B \& $B$, so that tourists can live in the Renaissance county and experience the culture and ecology of the Atayal people more thoroughly.

\subsection{Jinfeng Hot Spring, Jinfeng Township, Taitung County}

Jinfeng township is located in Jialan village, southwest of Taitung County and west of the South return road. There are three sources of hot springs, which are quite far away from each other. The first source of the hot spring is the old site of the geothermal exploration of CNPC. The water is not large and can reach knee deep. The water quality is clear and can be drunk and bathed. The water temperature is about 35 degrees centigrade. It seeps from the sand bed and is easy to submerge. The second source is 10 kilometers southwest of Jialan village, and the quality of the spring is similar to the first one. The third source, also known as Bilu hot spring, is a tributary in the northwest of Taimali, which can only be reached by walking for $4-5$ hours. The spring source is rich in water, and the water temperature is very high, about 70 degrees centigrade, which is completely different from the first two places. Because the location of Jinfeng hot spring is too far away from the village, the utilization rate is very low, only a few villagers use it for bathing.

\section{SWOT Analysis of Hot Springs with Development Characteristics of Indigenous People Tribes}

\subsection{Strengths}

Many indigenous tribes are located in high mountains. The hinterland and development scale are small, and the natural resources are rich. They have unique indigenous cultural characteristics. Therefore, under the promotion of the development of hot springs, we should develop in the form of the original people's characteristics of the tribe, rather than blindly pursue the tourism experience of the development type of large-scale hot spring hotel, and create a unique and unique hot spring tribal development form. The development of the hot spring demonstration area can cooperate with the characteristics and environment of different local tribes, develop hot spring products with economic value or participate in different forms of activities, so that the development of the hot spring can integrate the product orientation of hot spring, culture, tourism and agricultural products resources, and enhance the competitiveness of the tribe. In addition, due to the different cultural characteristics of the indigenous people and the fact that many hot springs are located in the indigenous areas in Taiwan, the combination of indigenous culture and hot spring culture has become a unique new cultural thinking and enjoyment, which can create the hot spring culture and cultural roots of the indigenous people and become an important part of the industrial development of the indigenous people. 


\subsection{Weaknesses}

Even the indigenous people are willing to invest in the hot spring industry, they will face difficulties in obtaining development funds and land use problems. If the land is reserved by the indigenous people, it is difficult to mortgage the land, because it is difficult to use the land for financing according to law. Comparatively speaking, it will be more difficult for Han people to obtain funds, and the public sector's assistance is needed to do a good job in obtaining and supplying funds, so as to provide indigenous people with the use of funds to solve this problem.

Due to the fact that the development schedule of the hot spring area involves the acquisition of land and water rights, the establishment of enterprises, the development permission, the planning and design, the obtaining of labels and the operation mode and other relevant legal procedures, which need to be reviewed and implemented by the committee members for many times. In particular, indigenous hot spring areas are located in mountainous areas, which are restricted by local geographical conditions and complicated regulations. In particular, after the promulgation of the "Hot Spring Law", Article 31 stipulates that those who have developed hot spring users who fail to obtain legal registration within a certain period of time shall have a 10 -year buffer period for improvement.

However, at present, the proportion of indigenous businesses obtaining legal seals is relatively low. The reasons include land acquisition problems: for example, hot spring businesses are located in river areas; or hot spring operators are not indigenous people and cannot obtain the land consent from the TCIP; or the buildings are inconsistent with business registration or land use, so they are unable to obtain water rights. Or the agricultural and animal husbandry land located in the hillside conservation area of non-urban land can be applied for development permission only after the hot spring area is designated by the tourism authority. Therefore, over the years, the delay of legalization procedures of indigenous individuals or businesses is mostly caused by the incomplete land leasing procedures or permitted use projects. The management and implementation of relevant laws and regulations involve many administrative agencies. If there is no proper treatment and relevant legal guidance, it will certainly affect the overall industrial development of the indigenous hot spring areas in the future [6].

In addition, there is a more serious problem. Since almost half of the indigenous population live in the metropolitan areas, the tribes only have the elderly and young children on weekdays, which also makes the inheritance of tribal culture and economic development in a dilemma [7] [8]. Because the need for management talents is the key to the development of indigenous industries, but the aging of the tribal population and the economic depression make the young people have to go out to work for food and clothing. As a result of the outflow of population, the problems of the tribe become more serious and the traditional value system of the tribe is more difficult to maintain [9]. 


\subsection{Opportunities}

Although in today's leisure society, there are a certain proportion of people who travel to the indigenous tribes on holidays every year, the most favorable thing for the indigenous people is the protection of the law. According to Article 17 of the "Taiwan'sBasic Law of the Indigenous People": the government shall protect the right to work of indigenous peoples, provide vocational training according to their social conditions and characteristics, assist them to obtain professional qualifications and technical personnel certificates, improve the employment service network of indigenous people, protect their employment opportunities and work rights, and receive fair remuneration and promotion. Due to the interaction of various internal and external adverse factors in Taiwan, it shows that the employment problem of indigenous people still needs strong and positive actions from the government, such as providing sufficient employment information, temporary and long-term job opportunities, vocational training, popularizing education standards, and reducing the gap between learning and using, so as to enhance the employment competitiveness of indigenous people. The government's advocacy of a stable and effective employment policy will help to improve the overall employment environment, promote the steady development of indigenous people employment, and then improve the quality of family life [10]. Therefore, the TCIP has formulated the "Work Security Law of the Indigenous People", the "Employment Program for the Indigenous People", and the "Economic and Industrial Development Plan of the Indigenous People" to ensure the participation of the indigenous people in the development plan of the hot spring demonstration area.

\subsection{Threats}

At present, the development of existing hot springs in Taiwan's indigenous villages and towns is mostly invested and built by Han people. The indigenous people are often left in the roles of head, employment, land leasing, etc., and are not operators. In addition, there is another serious problem, that is, the operators of outside nonindigenous people make use of the simplicity and incomprehension of the tribal residents and use other improper means to develop hot springs in the form of head development or joint cooperation. As a result, the tribe did not obtain substantial benefits, and caused a large number of hot spring resources to be extracted, and the tribal environment was damaged. As a result, the tribe did not obtain substantial benefits, and caused a large number of hot spring resources to be extracted, and the tribal environment was damaged. In particular, the indigenous people are lack of professional knowledge in the development and management of hot springs, so they are difficult to enter the competitive market of hot spring development without assistance and guidance. As hot spring development and promotion need continuous financial subsidies and professional counseling strategies, it is difficult to recycle under the condition of lack of government funds and a lot of restrictions on the use of hot 
springs, which often leads to the plight of lack of funds and lack of effectiveness in promoting the development of hot springs.

\section{Conclusions and Suggestions}

\subsection{Conclusions}

According to the results of SWOT analysis, the advantages and disadvantages of developing hot spring demonstration areas in the indigenous people areas are as follows: 1) in terms of advantages, the indigenous tribes are rich in natural resources and have unique indigenous cultural characteristics, which can create distinctive and unique new cultural thinking and enjoyment. In addition, the unique hot spring products with economic value or participation in different forms of activities can make the tribe have the product orientation of integrating hot spring, culture, tourism and agricultural products resources, which can enhance the competitiveness of the tribe. In addition, the unique hot spring products with economic value or participation in different forms of activities can make the tribe have the product orientation of integrating hot spring, culture, tourism and agricultural products resources, which can enhance the competitiveness of the tribe. 2) In terms of disadvantages, the indigenous people are willing to invest in the hot spring industry, but they will face difficulties in obtaining development funds and land use problems. In addition, the aging of the tribal population, the economic depression, and the outflow of population result in the lack of hot spring management talents. 3) In terms of opportunities, because of the prevailing leisure culture in Taiwan, the "Basic Law of the Indigenous People", the "Work Security Law of the Indigenous People", the "Employment Program for the Indigenous People", and the regulations and planning assistance of the "Economic and Industrial Development Plan of the Indigenous People", the participation of the indigenous people in the development plan of the hot spring demonstration area is guaranteed. 4) In terms of threat, the development of the existing hot springs in the indigenous villages and towns is mostly invested and built by Han people. The indigenous people often fall into the roles of head, employment and land lease. The tribes have not obtained substantial benefits, a large number of hot spring resources have been squeezed out and the tribal environment has been damaged. In particular, the indigenous people are lack of professional knowledge in the development and management of hot springs, and they are difficult to enter the competitive market of hot spring development without assistance and guidance.

\subsection{Suggestions}

As Taiwan's hot spring industry is almost dominated by Han consortia, many of which are high-end hot spring hotels. If the indigenous people want to develop the hot spring industry, they can hardly compare with it. The reason is that the scale of operation, financial resources, management ability and marketing ability of the Han people in hotels are better than those of the indigenous people who 
are inexperienced and lack capital and management ability. The researchers visited six hot spring demonstration areas to be developed and found that the facilities were simple, some places were not open, or they could only soak their feet. Therefore, the gap between TCIP and the hot spring industry operated by Han people is too big to attract people to consume. Therefore, the researchers suggest that the hot spring demonstration area to be developed should be combined with the ecological and cultural in-depth tourism of the tribe, and be combined into products, so as to attract people to experience. In addition, in order to avoid the rich hot spring resources of the aboriginal tribes, the lack of start-up funds or the dominance of Han consortia, the development of tribal hot springs urgently needs the financial support of government departments, and help transform the hot spring industry into tribal hot spring industry after the completion of hardware construction. It is better to construct a mechanism to promote the continuous investment and promotion of funds, and create recycling returns, rather than continuous funding subsidies, which are only reduced to the nature of relief.

\section{Acknowledgements}

This study was supported by a grant from National Social Science Foundation of China (No.18BMZ130).

\section{Conflicts of Interest}

The authors declare no conflicts of interest regarding the publication of this paper.

\section{References}

[1] Huang, H.C., Liu, C.H. and Chang, H.M. (2015) Does Tourism Development Bring Positive Benefit to Indigenous Tribe? Case by Dongpu in Taiwan. Advances in Research, 4, 235-246. https://doi.org/10.9734/AIR/2015/15030

[2] Huang, Y.X. (2014) Social Welfare of Residents: Problem Analysis and System Construction. Two Leaf Bookshop, Taipei, 246-270.

[3] Taiwan Council of Indigenous Peoples (2010) Economic and Industrial Development Plan of the Indigenous People (2010-2012). Taiwan Council of Indigenous Peoples, New Taipei.

[4] Taiwan Council of Indigenous Peoples (2015) Economic and Industrial Development Plan of the Indigenous People (2014-2017). Taiwan Council of Indigenous Peoples, New Taipei.

[5] Hu, Q.-L. (2010) Hot Spring Management-Hot Spring Method \& Promotion of Hot Spring Medical and Health Care and Training Materials for Hot Spring Service Personnel. Rainbow Hot Spring Resort. Taitung County, Taiwan.

[6] Zhou, Q.-N. (2006) Influencing Factors of Tourists' Search for Hot Spring Information: A Case Study of New Beitou Hot Spring. Unpublished Master's Thesis, Department of Enterprise Management, Central University, Taoyuan.

[7] Chang, H.-M., Hung, C.-H. and Chou, C.-L. (2018) A Study of Alishan Indigenous Tribal Tourism Development in Taiwan. Asian Journal of Environment \& Ecology, 
8, 1-12. https://doi.org/10.9734/AJEE/2018/45394

[8] Chang, H.-M. and Chang Liao, L.-C. (2014) A Study of Indigenous Tribe Tourism Planning and Developing-Case by Huanshan in Taiwan. Journal of International Management Studies, 9, 146-155.

[9] Chang, H.-M. and Huang, H.-C. (2014) A Study of Indigenous Tribe Tourism Planning and Developing-Case by Tamalung in Taiwan. Journal of International Management Studies, 9, 87-94.

[10] Taiwan Council of Indigenous Peoples (2016) Promotion of Employment for Indigenous People Phase III (2017-2020). Taiwan Council of Indigenous Peoples, New Taipei. 